\title{
Radiation-induced central demyelination, report of a rare subacute complication and review of the literature
}

\author{
Christopher R. Trevino' ${ }^{1}$ Arnold C. Paulino², Vinodh A. Kumar ${ }^{3}$, Nazanin Majd ${ }^{4}$, Marta Penas-Prado ${ }^{5}$ \\ 'Department of Medicine, Section of Hematology/Medical-Oncology, Tulane University School of Medicine, New Orleans, LA \\ 70112, USA. \\ ²Department of Radiation Oncology, UT MD Anderson Cancer Center, Houston, TX 77030, USA. \\ ${ }^{3}$ Department of Neuroradiology, UT MD Anderson Cancer Center, Houston, TX 77030, USA. \\ ${ }^{4}$ Department of Neuro-Oncology, UT MD Anderson Cancer Center, Houston, TX 77030, USA. \\ ${ }^{5}$ Neuro-Oncology Branch, National Cancer Institute, NIH, Bethesda, MD 20814, USA.
}

Correspondence to: Dr. Christopher R. Trevino, Department of Medicine, Section of Hematology/Medical-Oncology, Tulane University School of Medicine, 1430 Tulane Ave. \#8087, New Orleans, LA 70112, USA. E-mail: ctrevino@tulane.edu; Dr. Marta Penas-Prado, Neuro-Oncology Branch, National Cancer Institute, NIH, 9030 Old Georgetown Road, Building 82, Bethesda, MD 20814, USA. E-mail: marta.penas-prado@nih.gov

How to cite this article: Trevino CR, Paulino AC, Kumar VA, Majd N, Penas-Prado M. Radiation-induced central demyelination, report of a rare subacute complication and review of the literature. Neuroimmuno/ Neuroinflammation 2021;8:146-53. http://dx.doi.org/10.20517/2347-8659.2020.24

Received: 30 Mar 2020 First Decision: 16 Jun 2020 Revised: 29 Jun 2020 Accepted: 16 Jul 2020 Available Online: 21 Jun 2021

Academic Editor: Athanassios P. Kyritsis Copy Editor: Cai-Hong Wang Production Editor: Tian Zhang

\begin{abstract}
A 26-year-old woman with a right frontal diffuse astrocytoma, isocitrate dehydrogenase-mutant, WHO Grade II was treated with resection and radiotherapy (54 Gy in 30 fractions by volumetric modulated arc therapy). Ten weeks after radiation, she developed left leg weakness, and a brain magnetic resonance image demonstrated multifocal acute demyelinating brain lesions within regions that received 10-30 Gy. She improved with high dose steroids and subsequently resumed temozolomide. She had no prior history of a demyelinating disorder. The mechanisms of neurotoxicity from radiation include vascular injury, demyelination, and oxidative damage to neural stem cells and oligodendrocytes; though the pathophysiology is not fully understood. Subacute demyelination in the absence of known demyelinating disease is rare with only four cases previously described. This rare complication can be successfully managed with steroids when symptomatic. It is important to consider demyelination if new distant enhancing lesions arise following radiation of a primary brain tumor when findings are atypical for recurrence.
\end{abstract}

Keywords: Demyelination, radiation, astrocytoma, glioma 


\section{INTRODUCTION}

External beam radiation is a critical component for the management of many primary and secondary brain tumors, with evidence of attaining disease control and improving survival ${ }^{[1-4]}$. Unfortunately, this benefit is occasionally associated with radiation induced injury to the normal surrounding brain parenchyma. The mechanisms of neurotoxicity from radiation therapy include vascular injury and demyelination, although the pathophysiology is not well understood ${ }^{[5]}$. We present a case of an unusual subacute complication of radiation treatment in a patient with a primary brain tumor.

\section{CASE REPORT}

A 26-year-old woman with a non-enhancing, right frontal diffuse astrocytoma, isocitrate dehydrogenase (IDH)-mutant, WHO Grade II with alpha thalassemia/mental retardation syndrome X-linked loss and unknown O6-methylguanine DNA methyltransferase (MGMT) promoter methylation status who had received a biopsy followed by $95 \%$ tumor resection was treated with external beam radiation with 54 Gray (Gy) in 30 fractions ( $\mathrm{fx}$ ) by volumetric modulated arc therapy without concurrent chemotherapy. She tolerated her treatment well without focal neurologic symptoms initially. Her first post-radiation magnetic resonance image (MRI) brain 6 weeks after completion was stable, and she began cycle 1 of adjuvant standard dosed temozolomide at $150 \mathrm{mg} / \mathrm{m}^{2} /$ day for 5 consecutive days and tolerated it well. However, 10 weeks after completing radiation, she developed acute onset left leg weakness and presented to the emergency department. Her MRI brain demonstrated multiple new T2/Fluid Attenuation Inversion Recovery (FLAIR) hyperintense lesions in the right posterior parasagittal frontal lobe, left anterior frontal lobe, and the left periventricular white matter. Some of the lesions demonstrated incomplete ring enhancement which was most prominent in the right frontal lobe lesion. Imaging findings were consistent with acute multifocal demyelination. These lesions were distant from the high isodose component of the radiation field [Figure 1A-C]. Her symptoms localized to her right frontal lobe lesion. Her temozolomide was withheld, and she was evaluated with a lumbar puncture which demonstrated o red blood cells (RBCs) per high power field (HPF), 4 white blood cells (WBCs) per HPF (97\% lymphocytes, 3\% histiocytes), an elevated protein $(60 \mathrm{mg} / \mathrm{dL}$ ), normal glucose $(65 \mathrm{mg} / \mathrm{dL}$ ), and elevated myelin basic protein at $8.93 \mathrm{ng} / \mathrm{mL}$ (normal $<5.50 \mathrm{ng} / \mathrm{mL}$ ). There were no malignant cells on cytology. Immunoglobulin $\mathrm{G}$ (IgG) index and oligoclonal bands were not obtained due to problems with the sample. MRIs of the cervical, thoracic, and lumbar spine were normal with no demyelinating lesions in the spinal cord and no leptomeningeal disease. One week later, another MRI brain with advanced brain tumor imaging was performed prior to initiating steroids. The conventional MRI brain imaging findings remained unchanged. The advanced imaging demonstrated no significant elevation of the vascular permeability on dynamic contrast enhanced (DCE) MR perfusion imaging and no elevation of the relative cerebral blood volume (rCBV) on dynamic susceptibility contrastenhanced MR perfusion imaging within the right posterior parasagittal lesion in the frontal lobe. In addition, MR spectroscopy revealed a choline to creatinine ratio of less than 2:1 with no significant decrease in the $\mathrm{N}$-acetylaspartate (NAA) peak [Figure 1D-F]. These features further supported radiation induced treatment changes consistent with demyelination. As these lesions did not have radiographic features of tumor growth or pseudoprogression, and it would be exceptionally rare for multifocal distant high-grade tumor recurrence to occur immediately after radiation in an IDH-mutated low grade astrocytoma, biopsy was not performed. Given the presence of symptoms, she was treated with 1 gram (g) of methylprednisolone intravenously (IV) daily for 3 days, followed by a prednisone taper. Cycle 2 of temozolomide was held, and she clinically improved with the steroid treatment. All her subsequent MRIs brain demonstrated interval decrease in size of the lesions [Figure 1G-I]. On further review of previous neurologic symptoms, she denied prior acute demyelinating episodes including symptoms concerning for optic neuritis, transverse myelitis, or focal neurologic deficits lasting $>24 \mathrm{~h}$. Her baseline imaging before starting radiation did not demonstrate any demyelinating lesions. She was able to safely resume cycle 2 of adjuvant temozolomide 4 months later and tolerated therapy well. 

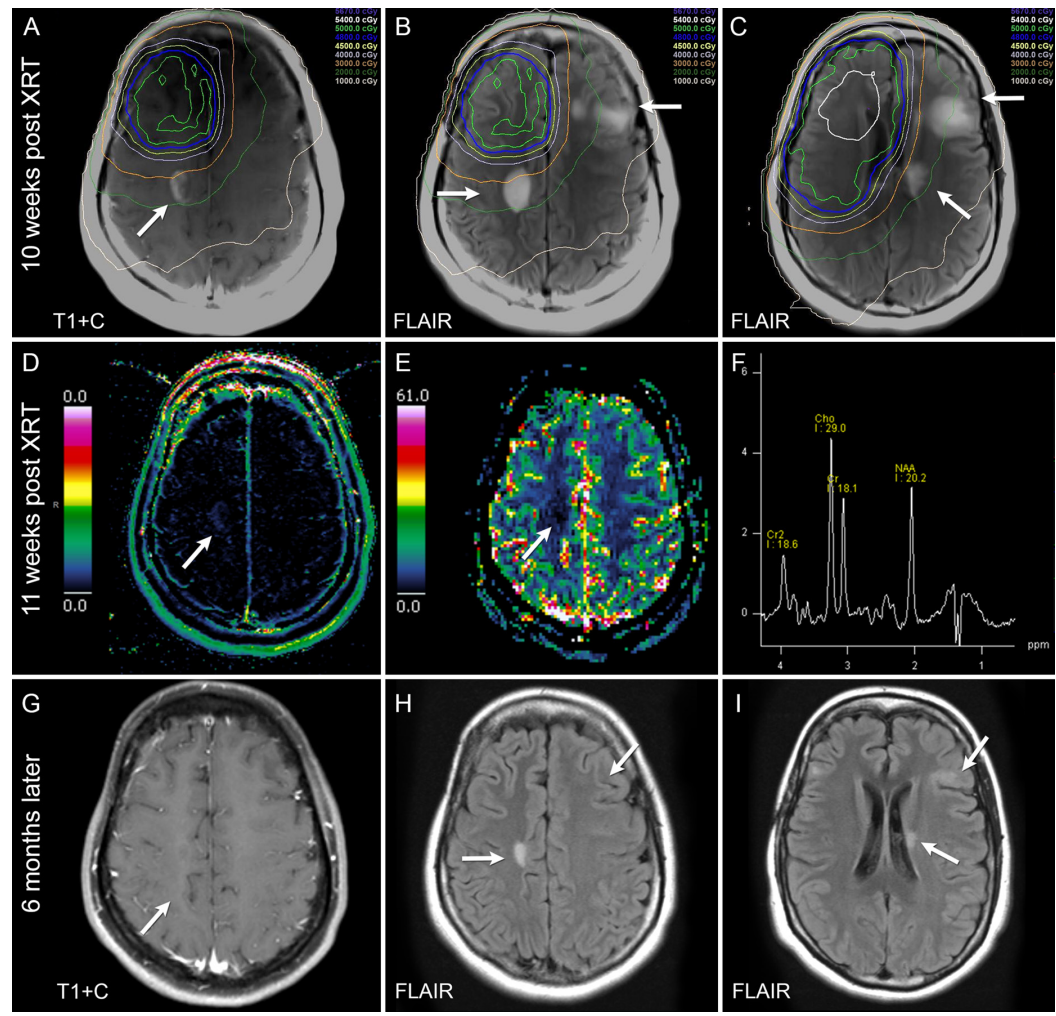

Figure 1. Top Row (A-C): Axial T1 post-contrast and FLAIR images with overlaid radiation treatment plan demonstrates an incomplete ring enhancing, FLAIR hyperintense lesion in the right posterior frontal lobe (A; arrow). There are also left frontal lobe juxtacortical non-enhancing white matter FLAIR hyperintense lesions (B, C; arrows) in the 1000-3000 cGy isodose zones. The imaging findings are consistent with acute demyelination. Middle Row (D-F): DCE perfusion MRI shows no significant increase in capillary permeability in the right posterior frontal lobe partially ring enhancing lesion ( $D$; arrow). Dynamic susceptibility contrast perfusion MRI reveals no elevation of the $\mathrm{rCBV}$ in the lesion ( $\mathrm{E}$; arrow). MR spectroscopy demonstrates a choline to creatinine ratio $<2: 1$ and no significant depression of the NAA peak in the right posterior frontal lesion (F). The advanced imaging features also support demyelination. Bottom Row (G-I): Six months later, there is no longer enhancement associated with the right posterior parasagittal frontal lobe lesion (G, arrow) and there is interval decrease in size of the white matter FLAIR hyperintense lesions bilaterally $(\mathrm{H}, \mathrm{I}$; arrows)

Fifteen months after completing radiation, she developed right-sided acute vision loss associated with painful eye movements without optic nerve edema on funduscopic exam, consistent with optic neuritis. Humphrey's visual field 30-2 demonstrated marked constriction of the visual field with generalized depression in the right eye and inferior visual field deficits in the left eye. Optical coherence tomography retinal nerve fiber layer was unremarkable in both eyes. A subsequent lumbar puncture demonstrated normal protein $(28 \mathrm{mg} / \mathrm{dL})$, o RBCs per HPF, and o WBCs per HPF. IgG index was normal and oligoclonal bands were negative. She was treated with $1 \mathrm{~g}$ of methylprednisolone IV daily for 3 days followed by prednisone $80 \mathrm{mg}$ by mouth for 11 days per the optic neuritis treatment trial ${ }^{[6]}$. She had significant improvement in her HVF testing with resolution of her pain. Her right optic nerve had received 41.6 Gy during radiation. She continues to be monitored for tumor recurrence and demyelinating episodes clinically and radiologically on surveillance imaging for tumor recurrence and demyelination without antitumoral or immunosuppressive treatment.

\section{DISCUSSION}

Central demyelination is a very rare subacute complication of radiation therapy and is important to distinguish from tumor progression due to implications on management. In our case, white matter lesions occurred subacutely in lower isodose zones ranging from 10-30 Gy, 10 weeks after completing radiation, similar to previously reported $\operatorname{cases}^{[7-10]}$. At the time of her multifocal acute demyelination, she had no prior history of a demyelinating disorder and did not fulfill criteria for multiple sclerosis by the 2017 revised 
McDonald Criteria ${ }^{[11]}$. Interestingly, she subsequently developed an episode of acute onset right sided anterior optic neuritis 15 months after radiation. Although the absence of oligoclonal bands or elevated IgG index were not present to support a diagnosis of multiple sclerosis, we could not unequivocally determine whether this episode was related or unrelated to previous radiation given the chronology.

Although there was no tissue obtained to pathologically verify demyelination, the radiographic features coupled with the sustained neurologic and radiographic response to steroids strongly supported demyelination as the diagnosis. For patients with symptomatic lesions and imaging that is concerning for pseudoprogression or true tumor growth, or when imaging is not clear for an etiology, a representative biopsy can clarify the diagnosis and assist in management. Additionally, if empiric treatment failed to improve symptoms and radiologic findings, the authors advocate for re-imaging, and considering biopsy to clarify diagnosis and guide next steps in treatment.

Even though the closest therapy to the central demyelination was temozolomide, there is little evidence to suggest chemotherapy was the cause of demyelination. Thus far temozolomide has not been associated with an increased risk of demyelination. Temozolomide has been safely used in patients with multiple sclerosis when treating a primary brain tumor (oligodendroglioma, WHO Grade II) ${ }^{[12]}$. Although this level of support is not generalizable for all patients with demyelinating diseases, the fact that subsequent cycles of temozolomide did not induce additional central demyelination for our patient suggests that demyelination is more likely a complication of radiation. In contrast, there is a larger volume of literature that clearly identifies radiation as a cause of central demyelination for patients with known underlying demyelinating disease $^{[13]}$. One possibility that remains unclear is if there is a combined neurotoxic effect from layering central nervous system (CNS) damaging agents with sequential radiation and temozolomide. However, there is strong evidence demonstrating improved survival in patients with grade II astrocytomas when using with adjuvant temozolomide, which cannot be replaced by use of chemotherapy at recurrence ${ }^{[4]}$. Though this case brings additional considerations when layering CNS damaging agents, the authors do not suggest changing management for low grade gliomas based on this case alone.

The pathophysiology of radiation-induced CNS injury is not well understood. It is believed to be due to vascular injury and demyelination based on histologic findings due to involvement of endothelial cells and oligodendrocytes ${ }^{[5]}$. Endothelial injury leads to reduced permeability, inducing astrocyte injury and swelling, followed by increased vasogenic edema with local ischemia and reperfusion injury culminating in white matter necrosis. Parallel to this process, endothelial cell loss and reduced vascular density lead to upregulation of adhesion molecules, white cell adhesion, perivascular cuffing, and cytokine release, causing oligodendrocyte apoptosis with demyelination and also contributing to white matter necrosis ${ }^{[5]}$.

The classically described risk factors associated with radiation-induced toxicity include radiation with greater than 2 Gy per fraction, total dose greater than $60 \mathrm{~Gy}$, large volume of radiation, and hypofractionated course of radiation ${ }^{[14]}$. Neurotoxicity is greatest after treatment with parallel-opposed radiotherapy fields encompassing the temporal lobes, brainstem, and central white matter of the brain ${ }^{[13]}$. Additionally, older age and concomitant comorbidities including diabetes mellitus or cerebrovascular disease also increase the risk of radiation-induced injury. Lastly, concurrent chemotherapy used as a radiation sensitizer and tumor specific factors including MGMT promoter methylation also increase the risk of radiation-induced toxicity ${ }^{[15,16]}$. Interestingly, none of these factors was present in this case, though MGMT status was unknown.

Radiation-induced neurotoxicity can be classified as acute (hours to days), subacute (within 6 months), or chronic (after 6 months) ${ }^{[5]}$. The greatest risk factor for development of acute radiation toxicity is the use of high doses of radiation therapy at greater than 3 Gy per fraction ${ }^{[17]}$, and is due to endothelial apoptosis resulting in blood brain barrier dysfunction with resultant cerebral edema. In contrast, subacute 
neurotoxicity is thought to be due to demyelination and can cause a variety of symptoms depending on the location $^{[13]}$. Both acute and subacute neurotoxicity are typically transient events, respond to steroids, and are not predictive of chronic neurotoxicity. Finally, chronic neurotoxicity is classified into 2 forms: a delayed radiation-induced necrosis (RN), or a delayed chronic progressive leukoencephalopathy. $\mathrm{RN}$ is a poorly understood process believed to result from endothelial dysfunction leading to normal brain parenchyma hypoxia and necrosis with excretion of vascular endothelial growth factor (VEGF) and can occur 3-6 months to years after completing radiation therapy ${ }^{[5]}$. $\mathrm{RN}$ responds to steroids in most cases, but when refractory requires anti-angiogenic therapy with bevacizumab, an anti-VEGF monoclonal antibody ${ }^{[18]}$. In contrast, leukoencephalopathy on imaging appears as confluent T2/FLAIR hyperintensities in the periventricular white matter which does not always correlate to clinically significant neurologic manifestations. When it does, it presents as a slowly, progressive neurodegenerative condition with clinical manifestations similar to primary degenerative dementia with no established treatment or reversibility, though some cases improve transiently with ventriculoperitoneal shunting similar to normal pressure hydrocephalus ${ }^{[19]}$.

The most frequent complication after radiation therapy of primary brain tumors is $\mathrm{RN}$ which often presents on post contrast MR imaging with soap bubble or swiss cheese like internal enhancement ${ }^{[20]}$ often associated with perilesional edema. Subacute demyelination in patients without a prior history of demyelinating disease is a rare entity with only a few cases described in the literature ${ }^{[7-10]}$. There are only 4 reported cases describing radiation-induced demyelination in patients without a prior history of demyelinating disease. Most cases are young women aged between 26-39, receiving greater than 50 Gy of radiation dose and developing this complication in the subacute time period ranging from 10 to 13 weeks after treatment; all were significantly symptomatic with variable response to steroids [Table 1].

The early reported cases were from 1959-1968 published by Lampert et al. ${ }^{[7]}$, Lampert and Davis ${ }^{[8]}$, Monro and Mair ${ }^{[9]}$. These 3 patients received antiquated radiation techniques which are well-known to be less precise compared to modern linear accelerator-based therapies and were associated with more frequent radiation-induced toxicities (first 3 cases on Table 1). These cases used 2D based planning and for the 2 cases with documented fractionation, the dose per fraction was 2.34-2.85 Gy (> $2 \mathrm{~Gy} / \mathrm{fx}$ ). No imaging modalities were available to identify the cause of neurologic deterioration so no steroid treatment was given, and all patients ultimately died with demyelination identified pathologically on autopsy. Although these cases may be associated with additional factors contributing to radiation-induced neurotoxicity, this represented the initial foundation that radiation may be associated with demyelination.

Of the 5 cases presented in Table 1, only two were primary brain tumors treated with modern radiation techniques and associated with primary brain tumor therapy, including our case presented above. Milic reported a 39-year-old woman with a left temporal oligodendroglioma (WHO Grade II) who presented similarly to our case with distant demyelinating symptomatic lesions 12 weeks after radiation that was successfully treated with steroids. Both cases were young women aged 26 and 39 who received $1.8 \mathrm{~Gy} / \mathrm{fx}$ (total dose 54 and $56 \mathrm{~Gy}$ ). In both cases, symptomatic demyelination occurred 10-12 weeks after completing radiation in brain regions distant to high isodose curves. Both were successfully identified on imaging and improved with steroids.

Interestingly, in our case, subacute demyelination occurred within the lower isodose zones ranging from 10-30 Gy and spared the high isodose zones. We propose that subacute demyelination after radiation therapy is rare because a complex set of environmental and genetic susceptibility patterns must be present for demyelination to occur, as seen in other demyelinating disorders. For example, murine models for multiple sclerosis implicate specific loci in chromosome 14 associated with susceptibility to virus-induced demyelinating disease, and genome-wide association studies led to the discovery of a single nucleotide polymorphism in the TNFRSF1A gene, which encodes tumor factor necrosis receptor 1 , and is associated 
Table 1. Case details of reported radiation induced demyelination without prior history of demyelinating disease

\begin{tabular}{|c|c|c|c|c|c|c|}
\hline Source & $\begin{array}{l}\text { Age/ } \\
\text { Gender }\end{array}$ & $\begin{array}{l}\text { Initial diagnosis } \\
\text { and location }\end{array}$ & $\begin{array}{c}\text { Radiation } \\
\text { dose }\end{array}$ & $\begin{array}{c}\text { Demyelination } \\
\text { symptoms and timing }\end{array}$ & $\begin{array}{l}\text { Imaging or pathology } \\
\text { finding of lesion }\end{array}$ & Clinical course \\
\hline Lampert et al. ${ }^{[7]} 1959$ & $32 / F$ & $\begin{array}{l}\text { Basal cell } \\
\text { carcinoma at left } \\
\text { external auditory } \\
\text { meatus }\end{array}$ & $\begin{array}{l}57 \mathrm{~Gy} \text { in } \\
20 \mathrm{fx}\end{array}$ & $\begin{array}{l}\text { Blurred vision, diplopia, } \\
\text { nausea, vomiting, and } \\
\text { ataxia } 2.5 \text { months post } \\
\text { radiation }\end{array}$ & $\begin{array}{l}\text { Pathology: } \\
\text { Demyelination } \\
\text { of left temporal } \\
\text { lobe, thalamus, left } \\
\text { cerebellum, inferior } \\
\text { pons, and entire } \\
\text { medulla }\end{array}$ & $\begin{array}{l}\text { Progressed to akinetic } \\
\text { mutism followed by } \\
\text { decorticate posturing } \\
\text { and died } 1 \text { month later }\end{array}$ \\
\hline $\begin{array}{l}\text { Lampert and Davis }{ }^{[8]} \\
1964\end{array}$ & $64 / M$ & Tonsil carcinoma & $\begin{array}{l}57.02 \mathrm{~Gy} \\
\text { in } 24 \mathrm{fx}\end{array}$ & 13 weeks post radiation & $\begin{array}{l}\text { Pathology: } \\
\text { Demyelination of } \\
\text { lower pons and upper } \\
\text { medulla }\end{array}$ & $\begin{array}{l}\text { Died } 1 \text { week after } \\
\text { symptom onset, no } \\
\text { treatment }\end{array}$ \\
\hline $\begin{array}{l}\text { Monro and Mair }{ }^{[9]} \\
1968\end{array}$ & $56 / M$ & Pituitary adenoma & $38.62 \mathrm{~Gy}$ & $\begin{array}{l}\text { Lethargy, memory } \\
\text { loss, right arm and } \\
\text { leg weakness with } \\
\text { dysarthria } 2 \text { months } \\
\text { post radiation }\end{array}$ & $\begin{array}{l}\text { Pathology: } \\
\text { Left temporal loss } \\
\text { of myelin and axons } \\
\text { in white matter with } \\
\text { amygdala necrosis }\end{array}$ & $\begin{array}{l}\text { Developed progressive } \\
\text { somnolence, treated } \\
\text { with IV heparin, } \\
\text { continued to deteriorate } \\
\text { and died from left } \\
\text { perirenal hematoma. }\end{array}$ \\
\hline $\begin{array}{l}\text { Milic and Rees }{ }^{[10]} \\
2017\end{array}$ & $39 / F$ & $\begin{array}{l}\text { Left temporal } \\
\text { oligodendroglioma } \\
\text { (WHO Grade II) }\end{array}$ & $\begin{array}{l}56 \mathrm{~Gy} \text { in } \\
30 \mathrm{fx}\end{array}$ & $\begin{array}{l}12 \text { weeks post radiation } \\
\text { developed headache, } \\
\text { gait ataxia, complex } \\
\text { ophthalmoplegia, } \\
\text { right ptosis, left } \\
\text { facial weakness, and } \\
\text { appendicular ataxia }\end{array}$ & $\begin{array}{l}\text { Imaging: } \\
\text { New FLAIR } \\
\text { hyperintense } \\
\text { lesions with } 1 \\
\text { contrast enhancing } \\
\text { (bifrontal). Additional } \\
\text { periventricular and } \\
\text { juxtacortical FLAIR } \\
\text { hyperintense lesions. }\end{array}$ & $\begin{array}{l}\text { CSF demonstrated } \\
\text { oligoclonal bands } \\
\text { IV methylprednisolonex } \\
3 \text { days then prednisone } \\
\text { taper. } 2.5 \text { years later } \\
\text { alive with persistent } \\
\text { fatigue, limb ataxia, and } \\
\text { weight loss }\end{array}$ \\
\hline $\begin{array}{l}\text { Trevino et al., } 2020 \\
\text { (summarize of this } \\
\text { review article) }\end{array}$ & $26 / F$ & $\begin{array}{l}\text { Right frontal } \\
\text { diffuse } \\
\text { astrocytoma, } \\
\text { IDH1-mutant, } \\
\text { WHO Grade } \\
\text { II (ATRX loss, } \\
\text { unknown MGMT } \\
\text { promoter } \\
\text { methylation } \\
\text { status) }\end{array}$ & $\begin{array}{l}54 \mathrm{~Gy} \text { in } \\
30 \mathrm{fx}\end{array}$ & $\begin{array}{l}10 \text { weeks post- } \\
\text { radiation developed } \\
\text { left leg weakness and } \\
\text { hemiplegic gait. } \\
15 \text { months post- } \\
\text { radiation developed } \\
\text { right optic neuritis (optic } \\
\text { nerve received } 41.6 \mathrm{~Gy} \text { ) }\end{array}$ & $\begin{array}{l}\text { Imaging: } \\
\text { Bifrontal and left } \\
\text { periventricular FLAIR } \\
\text { hyperintense lesions } \\
\text { in the } 10-30 \mathrm{~Gy} \\
\text { isodose curve; some } \\
\text { lesions demonstrated } \\
\text { incomplete ring- } \\
\text { enhancement. }\end{array}$ & $\begin{array}{l}\text { CSF demonstrated } \\
\text { elevated protein and } \\
\text { elevated myelin basic } \\
\text { protein. Oligoclonal } \\
\text { bands and IgG index } \\
\text { were negative at the } \\
\text { time of optic neuritis. } \\
\text { Multifocal } \\
\text { demyelination } \\
\text { treated with IV } \\
\text { methylprednisolone } \\
\times 3 \text { days followed by } \\
\text { prednisone taper. } \\
\text { Symptoms improved } \\
\text { and the MRI lesions } \\
\text { resolved on follow up } \\
\text { imaging. } \\
\text { Optic neuritis } \\
\text { treated with IV } \\
\text { methylprednisolone } \times 3 \\
\text { days followed by } 11 \text { days } \\
\text { prednisone } 80 \text { mg per } \\
\text { ONTT }\end{array}$ \\
\hline
\end{tabular}

Most women were young with ages 26-39 while the men presented at older ages ranging from 56-64 years old. Most patients were treated with greater than $50 \mathrm{~Gy}$ and developed significant neurologic symptoms in the subacute period ranging from 10-13 weeks after completing radiation. All patients were significantly symptomatic with variable response to steroids. There were more frequent deaths or severe permanent neurologic symptoms in the earlier reported cases described from 1959-1968, and these patients were not treated with steroids. M: Male; F: Female; Gy: Gray; fx: fraction; EBRT: external beam radiotherapy; ADL: activities of daily living; GK: gamma knife; FLAIR: fluid attenuation inversion recovery; LP: lumbar puncture; MS: multiple sclerosis; MRI: magnetic resonance imaging; WHO: World Health Organization; IV: intravenous; IDH1: isocitrate dehydrogenase-1; ATRX: alpha thalassemia/mental retardation syndrome X-linked; MGMT: O6-methylguanine DNA methyltransferase; CSF: cerebral spinal fluid; IgG: Immunoglobulin G; mg: milligrams; ONTT: Optic Neuritis Treatment Trial

with multiple sclerosis, but not with other autoimmune disorders ${ }^{[2,22]}$. Taken together, this data argues against the common thought that radiation induced damage occurs only in the high isodose radiation zones.

In the early 1960s prior to both CT scan use and modern treatments for multiple sclerosis and demyelination, several patients ultimately progressed to death without treatment ${ }^{[7,8]}$. However, since the advent of MR brain 
imaging and widespread knowledge of demyelinating disease, acute symptomatic treatment of demyelination with steroids has led to a more rapid neurologic recovery.

Although rare, subacute radiation induced demyelination is a potential complication in brain tumor patients. If the demyelination is asymptomatic and was diagnosed solely as an isolated radiographic finding, it can be monitored with surveillance imaging. However, if it causes neurologic symptoms, it can be successfully managed with steroids. Subacute demyelination, albeit rare, should be on the differential diagnosis for new distant enhancing lesions with typical radiographic features following radiation in the primary brain tumor population, not to be mistaken for tumor progression.

\section{DECLARATIONS}

\section{Authors' contributions}

Made substantial contributions to conception and design of the case report, primary writing, and data acquisition, interpretation, and editing: Trevino CR

Substantial contributions for editing, data interpretation, and rationale for underlying mechanistic considerations for radiation-induced demyelination: Paulino AC, Kumar VA, Majd N, Penas-Prado M

\section{Availability of data and materials}

Not applicable.

\section{Financial support and sponsorship}

None.

\section{Conflicts of interest}

Disclaimer: This article was prepared while Dr. Penas-Prado was employed at the UT MD Anderson Cancer Center. The opinions expressed in this article are the author's own and do not reflect the view of the National Institutes of Health, the Department of Health and Human Services, or the United States government. All authors declared that there are no conflicts of interest.

\section{Ethical approval and consent to participate}

Not applicable.

\section{Consent for publication}

A written informed consent for publication was obtained.

\section{Copyright}

(c) The Author(s) 2021.

\section{REFERENCES}

1. Stupp R, Mason WP, Van Den Bent MJ, Weller M, Fisher B, et al. Radiotherapy plus concomitant and adjuvant temozolomide for glioblastoma. N Engl J Med 2005;352:987-96.

2. Arvold ND, Lee EQ, Mehta MP, Margolin K, Alexander BM, et al. Updates in the management of brain metastases. Neuro Oncol 2016;18:1043-65.

3. Buckner JC, Shaw EG, Pugh SL, Chakravarti A, Gilbert MR, et al. Radiation plus procarbazine, CCNU, and vincristine in low-grade glioma. N Engl J Med 2016;374:1344-55.

4. van den Bent MJ, Baumert B, Erridge SC, Vogelbaum MA, Nowak AK, et al. Interim results from the CATNON trial (EORTC study 26053-22054) of treatment with concurrent and adjuvant temozolomide for 1p/19q non-co-deleted anaplastic glioma: a phase 3, randomised, open-label intergroup study. Lancet 2017;390:1645-53.

5. Giglio P, Gilbert MR. Cerebral radiation necrosis. Neurologist 2003;9:180-8.

6. Beck RW, Cleary PA. Optic neuritis treatment trial: one-year follow-up results. Arch Ophthalmol 1993;111:773-5.

7. Lampert P, Tom M, Rider W. Disseminated demyelination of the brain following Co60 (gamma) radiation. Arch Pathol 1959;68:322-30. 
8. Lampert PW, Davis RL. Delayed effects of radiation on the human central nervous system; Early and late delayed reactions. Neurology 1964;912-7.

9. Monro P, Mair W. Radiation effects on the human central nervous system 14 weeks after x-radiation. Acta Neuropathol 1968;11:267-74.

10. Milic M, Rees JH. Acute demyelination following radiotherapy for glioma: a cautionary tale. Pract Neurol 2017;17:35-8.

11. Thompson AJ, Banwell BL, Barkhof F, Carroll WM, Coetzee T, et al. Diagnosis of multiple sclerosis: 2017 revisions of the McDonald criteria. Lancet Neurol 2018;17:162-73.

12. Flowers A. Control of both oligodendroglioma and multiple sclerosis with chemotherapy with temozolomide: case report. Neurology 2013;80:105.

13. Miller RC, Lachance DH, Lucchinetti CF, Keegan BM, Gavrilova RH, et al. Multiple sclerosis, brain radiotherapy, and risk of neurotoxicity: the Mayo Clinic experience. Int J Radiat Oncol Biol Phys 2006;66:1178-86.

14. Marks JE, Wong J. The risk of cerebral radionecrosis in relation to dose, time and fractionation. A follow-up study. Prog Exp Tumor Res 1985;29:210-18.

15. Dörr W, Hendry JH. Consequential late effects in normal tissues. Radiother Oncol 2001;61:223-31.

16. Brandes AA, Franceschi E, Tosoni A, Blatt V, Pession A, et al. MGMT promoter methylation status can predict the incidence and outcome of pseudoprogression after concomitant radiochemotherapy in newly diagnosed glioblastoma patients. J Clin Oncol 2008;26:2192-7.

17. Soussain C, Ricard D, Fike JR, Mazeron JJ, Psimaras D, et al. CNS complications of radiotherapy and chemotherapy. Lancet 2009;374:1639-51.

18. Levin VA, Bidaut L, Hou P, Kumar AJ, Wefel JS, et al. Randomized double-blind placebo-controlled trial of bevacizumab therapy for radiation necrosis of the central nervous system. Int J Radiat Oncol Biol Phys 2011;79:1487-95.

19. Thiessen B, DeAngelis LM. Hydrocephalus in radiation leukoencephalopathy: results of ventriculoperitoneal shunting. Arch Neurol 1998;55:705-10.

20. Kumar AJ, Leeds NE, Fuller GN, Van Tassel P, Maor MH, et al. Malignant gliomas: MR imaging spectrum of radiation therapy-and chemotherapy-induced necrosis of the brain after treatment. Radiology 2000;217:377-84.

21. Gregory AP, Dendrou CA, Attfield KE, Haghikia A, Xifara DK, et al. TNF receptor 1 genetic risk mirrors outcome of anti-TNF therapy in multiple sclerosis. Nature 2012;488:508-11.

22. Bureau JF, Drescher KM, Pease LR, Vikoren T, Delcroix M, et al. Chromosome 14 contains determinants that regulate susceptibility to Theiler's virus-induced demyelination in the mouse. Genetics 1998;148:1941-9. 